\title{
Is there another consultant lifestyle?
}

\author{
ALAN PENTECOST
}

It so happened that I read the article by $\mathrm{Mr}$ Hill and his colleagues on manpower imbalance in obstetrics and gynaecology" in the same week that I saw the film "Gandhi." The similarities were astonishing. Much of the article read like the colonialists' talk in the last days of the empire. There was, essentially, a need to maintain the status quo. Obstetrics was a special case, to be compared to the more "contemplative" specialties such as general medicine. (I do hope that when I am admitted with my coronary or cerebrovascular accident the physician is not too contemplative.) No mention was made of other specialties, such as general surgery, orthopaedics, or anaesthesia, which might provide an equally pressing argument.

I must declare an interest here. I work in an obstetric unit that employs only consultants and senior house officers. Worse is to come-I actually prefer it that way. Granted, it was not my original choice, rather greatness forced on me. But now I would not have it otherwise. Registrars provide an easier lifestyle and undisturbed nights but in my experience they also lead to an increased incidence of poor patient management, unnecessary investigations, and a higher surgical complication rate. Some of us have an inborn error of metabolism that gives us a simple delight in doing things for people. Alas, it is probably incurable. I hardly know how to say it, but labour ward and emergency gynaecological management may actually be enjoyable.

This is not to admit to masochism. I no more wish to be roused from sleep than any other person. But, as later data will show, such recalls are not as frequent as might be thought. And, as a craftsman of sorts, there is a certain pleasure in seeing things done properly - so that the patients are safe and also satisfied. It is with some misgivings that I advocate a different lifestyle in such a public place. I have no wish to see consultants dragooned into a role that they do not want to adopt. Neither do I wish to be a pariah in medical circles. There does seem to be a suspicion that administrators in the Department of Health and Social Security might be trying to manipulate senior doctors, and, like Jeremiah the prophet, I would not wish to be seen to side with the enemy (if he exists). There is simply another way of looking at this problem. The three tier system of medical work is, after all, almost confined to the United Kingdom.

Is there any way that an alternative consultant lifestyle could be made more attractive? Money does not provide the answer in that it obeys the indirect hernia law-the more hernias the less money available for surgery. Furthermore, the proposal to make consultant salaries sensitive to workload was rejected by the profession. As a professional man I was not sorry. Perhaps the workload could be balanced according to whether the specialist post is "traditional" or that proposed by Renée Short's report."

Let us take a typical, 10 session a week consultant and allocate one session for each major part of the workload-firstly, the traditional consultant with a registrar and a one in three rota.

Operation lists, three sessions a week; clinics, three sessions;

\section{Maidstone, Kent \\ ALAN PENTECOST, FRCSE, FRCOG, consultant obstetrician and gynaecolo- gist}

Correspondence to: April Lodge, 24 Bower Mount Road, Maidstone, Kent ME16 8AU. rounds, one session; administration, one session; and on duty, two sessions (with registrar).

The work schedule for a specialist on a consultant and senior house officer unit could read as follows:

Operation lists, two sessions a week; clinics, two sessions; rounds, one session; administration, one session; and on duty, four sessions (no middle grade).

The "on duty" sessions are identical in terms of hours.

\section{Obvious flaws}

There are obvious flaws in a crude statistical attempt like this. But let it simply be the first suggestion, open to expansion, development, or cancellation. What is a clinic and how long is an operating list? Moreover, do we really want these things defined ? Furthermore, the work done will depend on the number of deliveries in the unit. All I can say from experience is that it seems to work in a district handling 1900 deliveries a year. We have had difficulties in integrating routine work and emergency cover but are now working on a new rota. I hope that this will bring us nearer to the ideal rota, which reads as follows:

Day 1-clinic and theatre list.

Day 2-labour ward and emergency cover.

Day 3-off duty.

In our unit two of the three consultants believe in this system and one of us would prefer to have a registrar. We have partially compensated him by allocating him the career senior house officer, leaving the two "radicals" with the vocational trainees. These latter are, of course, short on experience and surgical skills but are usually good communicators and tend to ensure patient satisfaction. Perhaps it is fallacious therefore to try to legislate too precisely as no unit is quite like another.

There are possibly two other ways in which the two tier unit could be made more attractive for the aspiring consultant.

Firstly, he should be encouraged to live near the unit. Personally, I have never found it necessary to live in the hospital as my home is only 5 or 10 minutes away. I propose a standard transport fee for each recall to the hospital irrespective of the distance travelled or the size of the vehicle. Why should the National Health Service subsidise a long drive or a large car? This could be worked out actuarially from the sums currently refunded on such travelling. The specialist would be financially encouraged to live near the unit and drive a smaller car. Most

Diary of hospital visits for 1982

\begin{tabular}{|c|c|c|c|c|}
\hline & \multicolumn{2}{|c|}{ NHS patients } & \multicolumn{2}{|c|}{$\begin{array}{c}\text { Private and staff } \\
\text { patients }\end{array}$} \\
\hline & $\begin{array}{c}\text { No of } \\
\text { calls }\end{array}$ & $\begin{array}{c}\text { Mean } \\
\text { duration } \\
\text { of stay } \\
\text { (minutes) }\end{array}$ & $\begin{array}{l}\text { No of } \\
\text { calls }\end{array}$ & $\begin{array}{c}\text { Mean } \\
\text { duration } \\
\text { of stay } \\
\text { (minutes) }\end{array}$ \\
\hline $\begin{array}{l}\text { Weekends and bank holidays: } \\
\text { Calls between } 0800 \text { and } 1400 \\
\text { Calls between } 1400 \text { and } 1800\end{array}$ & $\begin{array}{r}32 \\
8\end{array}$ & $\begin{array}{l}90 \\
39\end{array}$ & $\begin{array}{r}6 \\
11\end{array}$ & $\begin{array}{l}40 \\
33\end{array}$ \\
\hline $\begin{array}{l}\text { Evenings: } \\
\text { Calls between } 1800 \text { and } 2400^{*}\end{array}$ & 57 & 49 & 18 & 42 \\
\hline $\begin{array}{l}\text { Nights: } \\
\text { Calls between } 2400 \text { and } 0800\end{array}$ & 12 & 74 & 12 & 68 \\
\hline
\end{tabular}

"Includes 16 spontaneous "monitoring" visits, mean duration 23 minutes. 


\section{Fees paid by central government departments}

\author{
BMA agrees rise with Treasury
}

The BMA has reached an agreement with HM Treasury for increases in fees in the general schedule applicable for work in central government departments. In line with the government's response to the review body's 1983 report increases are being made from 1 April 1983 and 1 January 1984.

The minimum fee for an examination by a consultant goes up to 26 from 1 April, while the sessional fee has been increased from $£ 49$ to $£ 53$. The fee for a simple chest $x$ ray examination is increased to $f 19 \cdot 50$, rising to £20 from 1 January 1984.

For general practitioners a straightforward extract from records-for example, completion of form RM2-rises to $£ 4 \cdot 70$, and the fee for more complicated extracts from records to $£ 8 \cdot 10$. The sessional rates at medical boards and tribunals have been increased to $£ 45$ for chairmen and single doctor boards, and $£ 40$ for other medical boards. The minimum fee for regular attendance at government establishments has gone up to $£ 10 \cdot 50$.
Details of the current fees are available to members from the secretary of the BMA through head office or the regional offices. Members should quote their current membership number and the reference "Fees 21." A stamped addressed envelope would be appreciated.

Paragraphs 131 and 132 of the $B M A$ Fees Guide, which deal with family planning fees in hospital and NHS lecture fees, have been updated. Members who require this page should quote the reference "Fees 131."

\section{Ministry of Defence}

The BMA has reached agreement with the Treasury for an increase in the pay of full time medical practitioners working with the Ministry of Defence. The present salary of $£ 17000$ has been increased to $£ 18000$ with effect from 1 April and to $£ 18500$ from 1 January 1984

\section{BMA membership at 30 June 1983}

General practitioners

Senior hospital doctors

Junior hospital doctors

Community medicine and community health doctors

Civil Service doctors

Armed forces doctors

Occupational health

Medical academic staff

Members in practice but not identifiable by group

Total in practice

16632

1946

Retired members

Total UK membership

Total overseas membership

\section{Association Notice}

\section{Ophthalmic group committee}

\section{Nurses' statutory organisations}

The new unified structure for the education, training, registration, and discipline of nurses, midwives, and health visitors became fully operational on 1 July. The new structure (set out in Health Notice $(\mathrm{HN}(83) 20)$ circulated to health authorities in England) consists of a United Kingdom Central Council for Nursing, Midwifery, and Health Visiting and four national boards for England, Wales, Scotland, and Northern Ireland. The central council will be responsible for establishing and improving standards of education and training, profes- sional conduct and discipline, registration, and EEC matters. The English national board will be responsible for the provision of education and training, and related matters in England for nurses, midwives, and health visitors, and for investigating alleged professional misconduct. The statutory bodies dissolved on 1 July were the General Nursing Council for England and Wales, the Central Midwives Board, and the Council for the Education and Training of Health Visitors. towns have some pleasant housing in a central area near the hospitals.

Secondly, I believe that the home team should have a more definite say in the selection of a colleague. It should comprise half the selection committee-sufficient to ensure a wanted colleague without encouraging nepotism. The process of appointment by interview also needs to be assessed and perhaps replaced by the selection techniques applied in business.

The table shows the workload I carried last year. Calls between midnight and 8 am for NHS patients averaged about one a month. Evening calls averaged out at above five a month. Both of these figures may be lower than expected. But it must be borne in mind that this is for a 1900 delivery a year unit with three consultants.

If the two tier system of running an obstetric and gynaecological unit is adopted the consultants seem to fear three things. Firstly, there is a fear of fatigue. An analysis of the above figures suggests that this is probably illusory. Secondly, there is the fear of loss of status. This latter may come, however, from position or performance. Thirdly, there is the real possibility that private practice would be diluted by expanding the senior grade. The medical profession might, however, be expected to lead the way in choosing job satisfaction and leisure in preference to the continuous pursuit of wealth.

\section{References}

${ }^{1}$ Hill JG, Taylor RW, Basu HK. Manpower imbalance in obstetrics and gynaecology. Br Med f 1983;286:1159-62.

2 House of Commons Social Services Committee. Medical education with special reference to the number of doctors and the career structure in hospitals. Fourth report. London: HMSO, 1981. (Short report.)

(Accepted 5 May 1983) 